\title{
FENOLOGIA DE Tabebuia chrysotricha (IPÊ-AMARELO) NO AMBIENTE URBANO DE CURITIBA (PR)
}

\author{
Angeline Martini ${ }^{1}$; Daniela Biondi'; ${ }^{2}$ Antonio Carlos Batista ${ }^{3}$ \\ (recebido em 06.05.2011 e aceito para publicação em 15.12.2011)
}

\section{RESUMO}

Uma das maneiras de se interpretar a reação que as plantas têm com o meio urbano é o acompanhamento fenológico. O objetivo deste trabalho foi analisar a fenologia de Tabebuia chrysotricha cultivada no ambiente urbano em via pública. Para isso foram selecionados cinco exemplares plantados em calçadas pavimentadas e cinco em canteiro central com gramado, sujeitos às mesmas condições ambientais. O monitoramento, de caráter qualitativo, foi realizado quinzenalmente, entre os meses de janeiro e dezembro de 2010 . Foram avaliadas características referentes ao estado reprodutivo e vegetativo. Tais características foram relacionadas com dados meteorológicos obtidos junto ao Instituto SIMEPAR: valores médios diários de temperatura e umidade relativa do ar e os valores totais diários de precipitação e fotoperíodo. Foram medidas também variáveis relevantes para a arborização de ruas. Os resultados mais significativos encontrados mostram que os indivíduos plantados em calçadas pavimentadas apresentaram dimensões maiores. Embora a floração das árvores plantadas em canteiro central tenha sido mais longa, os indivíduos da calçada pavimentada apresentaram floração mais intensa e vistosa em um menor intervalo de tempo. Constatou-se que as variáveis meteorológicas influenciaram no comportamento da espécie, bem como as diferentes condições de plantio a que foram submetidas no meio urbano.

Palavras-chave: Fenofases; Variáveis meteorológicas; Arborização urbana.

\footnotetext{
1 Engenheira Florestal, Mestranda em Engenharia Florestal na Universidade Federal do Paraná/UFPR, Curitiba - PR, Brasil. E-mail: martini.angeline@gmail.com

2 Engenheira Florestal, Dra., Professora Associada II do Departamento de Ciências Florestais Universidade Federal do Paraná/UFPR, Curitiba - PR, Brasil. E-mail: dbiondi@ufpr.br

${ }^{3}$ Engenheiro Florestal, Professor Associado II do Dr., Depto. de Ciências Florestais da Universidade Federal do Paraná / UFPR, Curitiba - PR, Brasil. E-mail: batistaufpr@ufpr.br
} 


\title{
PHENOLOGY OF Tabebuia chrysotricha IN THE URBAN ENVIRONMENT OF CURITIBA (PR)
}

\begin{abstract}
One way to interpret plants' reaction to urban environment is phenological monitoring. The objective of this study was to examine the phenology of $T$. chrysotricha planted in urban areas on public roads. For this purpose we selected five individuals planted in paved sidewalks and five in central bed with lawn, subjected to the same environmental conditions. The qualitative monitoring was accomplished fortnightly, between January and December 2010. The characteristics of reproductive and vegetative states were evaluated. These characteristics were related to the following meteorological data, obtained from SIMEPAR Institute: average daily temperature and relative humidity and total values of daily rainfall and photoperiod. Relevant variables for urban forestry in streets were also measured. The most relevant results show that individuals planted in paved sidewalks present the highest dimensions. Although the flowering trees planted in the central flowerbed has been larger than the other ones, individuals in paved sidewalk presented more intense and showy flowers in a shorter period. The meteorological variables were found to influence the behavior of the species, as well as the urban areas different planting conditions.
\end{abstract}

Keywords: Phenophases; Meteorological variables; Urban forest.

\section{INTRODUÇÃO}

O uso de vegetação arbórea no meio urbano é bastante antigo, fazendo parte da história do homem desde as primeiras civilizações (SILVA; PAIVA; GONÇALVES, 2007). Este costume traz para as cidades um pouco do ambiente natural, com a finalidade de satisfazer as necessidades mínimas do ser humano (PEDROSA, 1983). Portanto desempenha um importante papel na qualidade de vida em ambientes urbanos (BIONDI; ALTHAUS, 2005)

A arborização urbana, seja nas áreas verdes ou na arborização de ruas, oferece à cidade inúmeros benefícios nos aspectos ecológicos, estéticos e sociais (BIONDI, 2008). 
Sendo esses benefícios gerados não somente pelas grandes áreas verdes, mas também pelas árvores plantadas ao longo das ruas, que formam a arborização viária.

São comuns os estudos que acompanham o desenvolvimento das plantas em seu ambiente natural. Geralmente estas informações são geradas pela fenologia, determinandose as fases da planta (fenofases) referentes à floração, frutificação, dispersão de sementes e foliação. Entretanto, o conhecimento sobre o seu desenvolvimento natural não é suficiente para garantir a eficiência da utilização de uma espécie no meio urbano, onde as condições são muito adversas.

Dentro dos núcleos urbanos, as diferentes condições de desenvolvimento proporcionadas às espécies arbóreas, tais como: impermeabilização, sombreamento, compactação do solo, alteração climática e ação predatória, dentre varias outras, são hostis ao seu crescimento (FEIBER, 2005). Desta maneira, muitas vezes, a espécie introduzida assume uma fenologia diferente dos padrões esperados, observados no meio natural, como a forma da copa, o tipo de raiz e a susceptibilidade a pragas, doenças e poluição (BIONDI; ALTHAUS, 2005).

Pouca ou quase nenhuma informação é disponibilizada sobre influência da composição dos canteiros sobre as árvores ali plantadas, bem como, sobre o atrativo destas paisagens ao bem estar dos pedestres (BOBROWSKI; BIONDI; BAGGENSTOSS, 2009).

O conhecimento fenológico das espécies que compõem a arborização urbana, submetidas a algum nível de estresse fisiológico, pode indicar, de acordo com o seu ritmo de fenofases em situação natural, a presença ou ausência de irregularidade no mesmo e, neste último caso, ser base para o planejamento de ações silviculturais que permitam uma melhor adaptação das espécies ao ambiente urbano (BRUN et al., 2007).

Como qualquer ser vivo cada espécie vegetal é dependente de condições ambientais favoráveis à sua sobrevivência e, além disso, ao seu adequado desenvolvimento (SCHUBERT, 1979). As exigências de uma espécie, variáveis em termos de condições climáticas e edáficas em interação, apresentam-se em níveis de limites mínimos e máximos, dentro dos quais se estabelecem faixas de valores ou características para um ótimo desenvolvimento biológico de cada espécie (SCHUBERT, 1979).

O acompanhamento fenológico é uma das ferramentas que podem ser aplicadas para interpretar a reação das plantas ao meio urbano. Pode ser entendido como a abordagem baseada no início e na duração de alterações visíveis no ciclo de vida das plantas correlacionadas com fatores climáticos (LARCHER, 2006). Por intermédio deste é possível determinar as fenofases da planta referentes à floração, frutificação e foliação (MARTINI et al., 2010).

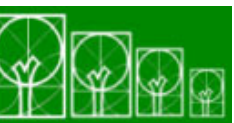

$\mathbf{S} \cdot \mathbf{B} \cdot \mathbf{A} \cdot \mathbf{U}$ Soc. Bras. de Arborização Urbana

REVSBAU, Piracicaba - SP, v.6, n.4, p. 51-67, 2011 
A organização das datas fenológicas proporciona informações ecológicas importantes sobre a duração média das diferentes fenofases das distintas espécies em uma área, sobre o local e sobre as diferenças determinadas pelo clima nas datas de início dessas fases (LARCHER, 2006). O mesmo autor afirma ainda que o registro da atividade biológica dos organismos pode servir para interpretar a reação que eles têm com o complexo climático do lugar.

As plantas estão sujeitas às variações ambientais locais que podem ter influência no comportamento fenológico (MARQUES; OLIVEIRA, 2004). Em conjunto com a regulação de mecanismos endógenos, os fatores ambientais influenciam a freqüência da floração, o início da frutificação e o amadurecimento das sementes, principalmente pelo efeito do estado nutricional (LARCHER, 2006).

$\mathrm{Na}$ cidade de Curitiba, uma das espécies mais utilizadas na arborização urbana é a Tabebuia chrysotricha (Mart. ex A. DC.) Standl. (Bignoniaceae), popularmente conhecida como ipê-amarelo, ipê-amarelo-cascudo ou ipê-do-morro (LORENZI, 1992). Ocorre na vegetação secundária das encostas da Floresta Atlântica, desde o estado da Paraíba até Santa Catarina (BACKES; IRGANG, 2004).

Segundo Biondi e Althaus (2005), é considerada a flor nacional do Brasil, devido a sua floração acontecer geralmente em setembro, especialmente no dia 7, dia da Independência do Brasil. Ou, devido também as suas flores serem amarelas e as folhas verdes que representam as cores do Pavilhão Nacional.

Segundo Backes e Irgang (2004), a espécie é bastante cultivada em cidades, especialmente em pequenos espaços, como calçadas e canteiros, onde um dos seus atrativos são as mudanças visuais sofridas durante todo o ano. A árvore fica desprovida de folhas no inverno, amplamente florida e amarela na primavera e foliada no verão.

A floração de Tabebuia chrysotricha, segundo Lorenzi (1992), ocorre de agosto a setembro, período no qual a planta também fica desprovida de folhas. Backes e Irgang (2004) indicam maior duração deste período, que inicia em agosto e se estende até novembro. Os frutos amadurecem a partir do final de setembro e meados de outubro (LORENZI, 1992) ou segundo Backes e Irgang (2004) de setembro a outubro. Biondi e Althaus (2005), em pesquisa com árvores de rua em Curitiba, indicam que a mudança foliar ocorre de agosto a setembro, período no qual a espécie apresenta flores. Na busca por gerar informações sobre o comportamento da espécie nas vias públicas, meio com características distintas do natural, este trabalho tem por objetivo analisar a fenologia de $T$. chrysotricha em diferentes condições de plantio. 


\section{MATERIAL E MÉTODOS}

O presente trabalho foi realizado na Avenida Prefeito Omar Sabbag, situada no bairro Jardim Botânico, na cidade de Curitiba-PR, a aproximadamente $25^{\circ} 26^{\prime} 34^{\prime \prime}$ de latitude sul e $49^{\circ} 14^{\prime} 44^{\prime \prime}$ de longitude oeste. A capital paranaense localiza-se no Primeiro Planalto a uma altitude média de 934,6 m acima do nível do mar (IPPUC, 2006).

Segundo a classificação de Köppen, a cidade de Curitiba localiza-se em região climática do tipo $\mathrm{Cfb}$, com clima subtropical úmido, mesotérmico, sem estação seca, com verões frescos e invernos com geadas freqüentes e ocasionais precipitações de neve. De acordo com o último estudo realizado pelo IPPUC entre os anos de 1998 e 2001, Curitiba apresenta temperatura média de $17,48^{\circ} \mathrm{C}$, precipitação média anual de $1571,28 \mathrm{~mm}$ e umidade média relativa do ar de 78,87\% (IPPUC, 2006).

A avenida Pref. Omar Sabbag apresenta duas pistas de rolamento, uma em cada sentido, com faixa dupla e área de estacionamento. É revestida com concreto betuminoso e recebe grande tráfego de veículos. Um canteiro central divide as pistas de rolamento. Este canteiro é composto por gramado e exemplares de Tabebuia chrysotricha, apresenta seis metros de largura e se estende ao longo de toda a avenida com interrupções apenas nos cruzamentos e retornos. Nas laterais das pistas de rolamento, encontram-se calçadas com $2,9 \mathrm{~m}$ de largura e revestidas com lousa (pedra com dimensões $20 \times 20 \mathrm{~cm}$ ). Nestas calçadas também foram plantadas Tabebuia chrysotricha, em canteiros que disponibilizam para as árvores uma área de permeabilidade média de $0,27 \mathrm{~m}^{2}$.

Foram selecionados cinco exemplares da espécie Tabebuia chrysotricha plantados no canteiro central com gramado e cinco plantados em calçadas pavimentadas, ambos na Av. Pref. Omar Sabbag (Figura 1), sujeitos às mesmas condições climáticas, para realização de um acompanhamento fenológico. Freqüentemente, o número de três indivíduos é suficiente para pesquisas com fenologia segundo Ramalho (1976). Neste trabalho, como não há referências de pesquisas com fenologia em áreas urbanas e para aumentar a confiabilidade dos resultados optou-se por uma amostragem maior. 
Figura 1. Localização dos exemplares cultivados no canteiro central (A) e na calçada pavimentada (B) da Avenida Prefeito Omar Sabbag, na cidade de Curitiba-PR

Figure 1. Location of specimens grown in central lawn (A) and paved sidewalk (B) of the Prefeito Omar Sabbag Avenue in the city of Curitiba- PR

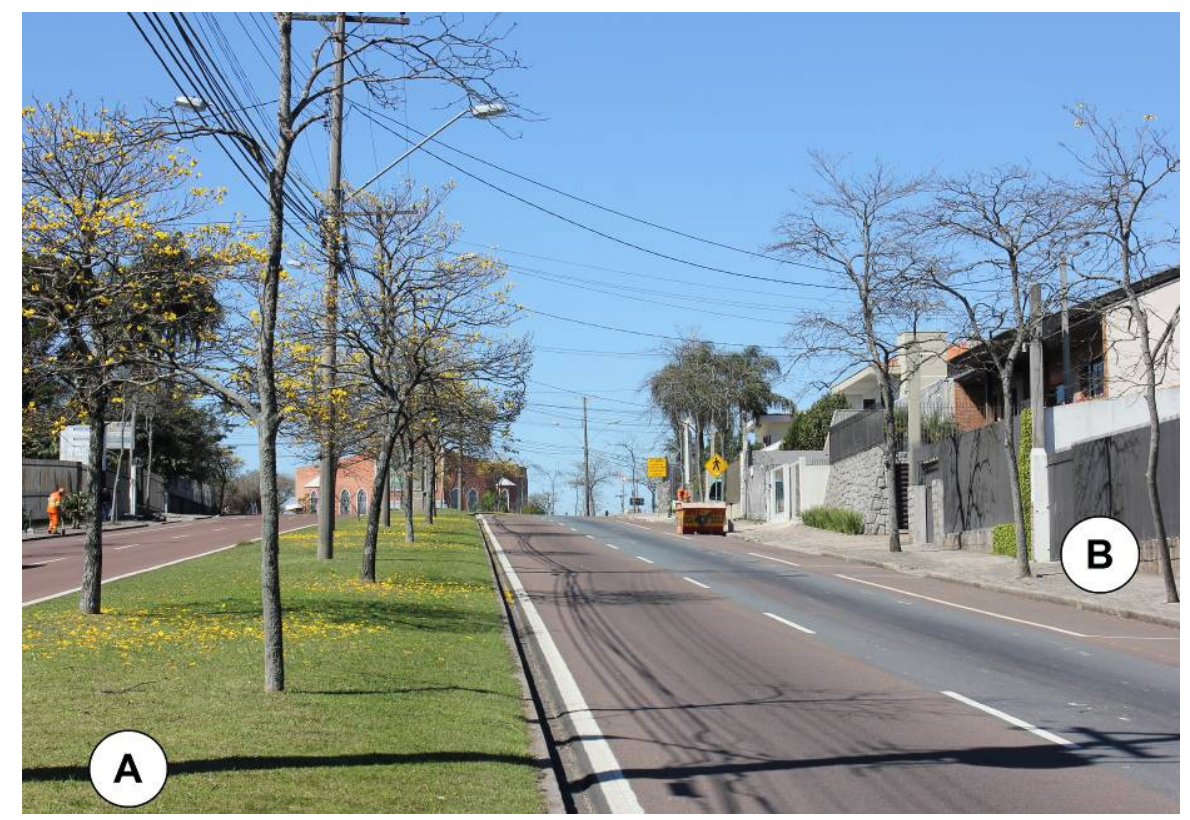

O acompanhamento fenológico foi realizado de maneira qualitativa, ou seja, foi observada apenas a presença ou ausência das fenofases nos indivíduos referentes às características reprodutivas e vegetativas. As observações foram conduzidas quinzenalmente entre os meses de janeiro a dezembro de 2010. Neste período, foram registradas a ocorrência das fenofases de florescimento (botões florais, floração adiantada, floração terminada), frutificação (frutos novos, frutos maduros, frutos caindo ou sementes dispersando), e perda e brotação das folhas (folhas novas, folhas maduras, queda de folhas e desfolhada). Para a elaboração do quadro fenológico, considerou-se em cada quinzena a fenofase predominante entre os exemplares.

As fenofases das plantas foram correlacionadas com dados meteorológicos obtidos junto ao Instituto SIMEPAR, situado aproximadamente a 1,5 $\mathrm{Km}$ do local de estudo. Estes dados, obtidos e processados quinzenalmente, foram: valores médios diários de temperatura $\left({ }^{\circ} \mathrm{C}\right)$, umidade relativa do ar $(\%)$ e os valores totais diários de precipitação $(\mathrm{mm})$ e fotoperíodo (h).

No início do monitoramento, foram medidas variáveis relevantes para a arborização de ruas - altura, altura de bifurcação, Circunferência a Altura do Peito (CAP) e diâmetro de copa das árvores, largura da calçada, área do canteiro, distância da árvore ao meio-fio, 
distância da árvore a fiação elétrica e distância entre árvores. A altura total e altura de bifurcação foram estimadas visualmente e os demais parâmetros foram medidos com o auxílio de fita métrica ou trena.

\section{RESULTADOS E DISCUSSÃO}

\section{Características da Árvore e do Ambiente}

As árvores amostradas nesta pesquisa estavam plantadas em condições de plantio diferenciadas: canteiro central, com maior área de permeabilidade e cobertura com gramínea, que permite melhor aeração do solo; e calçada pavimentada, com pequena área de permeabilidade, o que pode acarretar diversos problemas (desnutrição, falta de aeração do solo e déficit hídrico).

As variáveis referentes à árvore e ao ambiente na amostra de Tabebuia chrysotricha (Tabela 1) mostraram que os indivíduos plantados em calçadas pavimentadas, com menor área de permeabilidade, apresentaram dimensões maiores em todas as variáveis dendrométricas do que os indivíduos do canteiro central com gramado.

Tabela 1. Variáveis referentes aos indivíduos e ao ambiente Table 1. Variables related to individuals and the environment

\begin{tabular}{|c|c|c|c|c|c|c|c|c|c|c|}
\hline \multirow{7}{*}{ 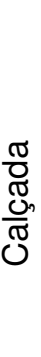 } & $N^{0}$ & $\begin{array}{l}\text { CAP } \\
(\mathrm{cm})\end{array}$ & $\underset{(\mathrm{m})}{\mathrm{H}}$ & $\begin{array}{l}\mathrm{Hb} \\
(\mathrm{m})\end{array}$ & $\begin{array}{l}\text { LC } \\
(\mathrm{m})\end{array}$ & $\begin{array}{c}\text { DMA } \\
(\mathrm{m})\end{array}$ & $\begin{array}{c}\mathrm{AC} \\
\left(\mathrm{m}^{2}\right)\end{array}$ & $\begin{array}{l}\text { DF } \\
(\mathrm{m})\end{array}$ & $\begin{array}{l}\text { DC } \\
(\mathrm{m})\end{array}$ & $\underset{(m)}{E}$ \\
\hline & 1 & 38,0 & 6,30 & 3,10 & 2,90 & 1,00 & 0,21 & - & 4,63 & 19,40 \\
\hline & 2 & 42,0 & 7,00 & 3,65 & 2,90 & 0,75 & 0,29 & - & 4,38 & 9,57 \\
\hline & 3 & 50,5 & 8,35 & 4,70 & 2,90 & 0,92 & 0,34 & - & 6,19 & 13,78 \\
\hline & 4 & 64,5 & 8,63 & 3,66 & 2,90 & 1,10 & 0,19 & - & 7,70 & 36,64 \\
\hline & 5 & 63,5 & 7,32 & 3,15 & 2,90 & 1,06 & 0,33 & - & 4,68 & - \\
\hline & Média & 51,7 & 7,52 & 3,65 & 2,90 & 0,97 & 0,27 & - & 5,51 & 19,85 \\
\hline \multirow{7}{*}{ 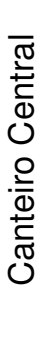 } & $\mathrm{N}^{\circ}$ & $\begin{array}{l}\text { CAP } \\
\text { (cm) }\end{array}$ & $\begin{array}{l}\mathrm{H} \\
(\mathrm{m})\end{array}$ & $\begin{array}{l}\mathrm{Hb} \\
(\mathrm{m})\end{array}$ & $\begin{array}{l}\text { LC } \\
\text { (m) }\end{array}$ & $\begin{array}{c}\text { DMA } \\
(\mathrm{m})\end{array}$ & $\begin{array}{l}\mathrm{AC} \\
\left(\mathrm{m}^{2}\right)\end{array}$ & $\begin{array}{l}\text { DF } \\
\text { (m) }\end{array}$ & $\begin{array}{l}\text { DC } \\
\text { (m) }\end{array}$ & $\begin{array}{c}\mathrm{E} \\
(\mathrm{m})\end{array}$ \\
\hline & 1 & 51,0 & 5,50 & 2,40 & 6,00 & 1,73 & 330,00 & 1,27 & 4,57 & 12,85 \\
\hline & 2 & 53,5 & 4,70 & 1,70 & 6,00 & 1,71 & 330,00 & 1,29 & 5,72 & 17,5 \\
\hline & 3 & 55,0 & 6,30 & 2,02 & 6,00 & 1,65 & 330,00 & 1,35 & 5,72 & 11,6 \\
\hline & 4 & 44,5 & 3,93 & 1,67 & 6,00 & 1,80 & 330,00 & 1,20 & 5,55 & 9,8 \\
\hline & 5 & 44,5 & 4,70 & 1,86 & 6,00 & 1,79 & 330,00 & 1,21 & 4,85 & - \\
\hline & Média & 49,7 & 5,03 & 1,93 & 6,00 & 1,74 & 330,00 & 1,26 & 5,29 & 12,94 \\
\hline
\end{tabular}

LEGENDA: CAP = circunferência a altura do peito; $\mathrm{H}=$ altura total; $\mathrm{Hb}=$ altura de bifurcação; $\mathrm{LC}=$ largura da calçada; $\mathrm{DMA}$ = Distância do meio-fio a árvore; $\mathrm{AC}$ = Área do canteiro; $\mathrm{DF}=$ distância da árvore ao fio de luz; $\mathrm{DC}=$ Diâmetro de copa; $\mathrm{E}=$ espaçamento entre árvores. 
A espécie apresentou um CAP médio na calçada, $2 \mathrm{~cm}$ maior do que no canteiro central. A altura total média na calçada pavimentada foi 2,5 m maior e altura de bifurcação 1,72 m. As árvores plantadas no canteiro central estavam sob a fiação elétrica, mais afastadas do meio fio e o espaçamento entre elas era menor.

As características estéticas dos indivíduos plantados em calçadas pavimentadas mostraram-se mais favorável, além de apresentarem dimensões maiores em todas as variáveis dendrométricas. Tal resultado contraria Milano e Dalcin (2000), quando afirmam que as árvores nas cidades, submetidas à compactação do solo, tem um pequeno crescimento. Além disso, a área de permeabilidade proporcionada aos indivíduos da calçada pavimentada $\left(0,27 \mathrm{~m}^{2}\right)$ está muito abaixo do recomendado por Santos e Teixeira (2001), que não deve ser inferior a $1 \mathrm{~m}^{2}$.

Resultados encontrados por Biondi (1995) mostram que as áreas pavimentadas em locais residenciais proporcionam melhores condições para o desenvolvimento das árvores em Perímetro a Altura do Peito (PAP). Os exemplares de Tabebuia chrysotricha plantados em canteiro com gramado, amostrados pela autora, também apresentaram dimensões menores em PAP e diâmetro de copa, além de outras variáveis medidas, referentes ao vigor da espécie.

Segundo Biondi e Althaus (2005), a impermeabilização e os restos de construções são responsáveis pela compactação, hidro-repelência, pH alterado, aeração deficiente, drenagem restrita, interrupção do ciclo de nutrientes, e modificação das atividades dos micro-organismos, ou seja, o solo no meio urbano é um produto do processo de urbanização que proporciona grandes alterações nas propriedades físicas e químicas.

Uma drenagem ruim, por exemplo, pode levar o solo a uma deficiência em oxigênio, o que limita a atividade radicular. Isto pode resultar na redução da assimilação de nutrientes e água, distorção do padrão das raízes e consequentemente menor crescimento e estabilidade da árvore (BRADSHAW; HUNT; WALMSLEY, 1995). No entanto, os resultados dessa pesquisa apresentaram resultados contrários aos dos autores citados.

O ambiente das árvores do canteiro com gramado sofre constantes modificações, com a incorporação de adubos orgânicos ou inorgânicos, revolvimento do solo, danos ao tronco com máquina de cortar grama e competição por umidade e nutrientes (BIONDI, 1995), o que pode explicar as menores dimensões encontradas nestes. Os indivíduos do canteiro central sofreram a influência da fiação elétrica sobre suas copas, tornando-se necessário práticas de podas para que seus galhos não alcancem os fios. 
Segundo Biondi e Althaus (2005), quando submetida à poda, a copa de uma árvore deve ter sua forma preservada e recuperada. Mas isto não ocorre nos indivíduos estudados, que demonstram aspectos bem distintos quanto à altura, forma e densidade de copa.

\section{Padrões Fenológicos}

As fenofases reprodutivas e vegetativas dos indivíduos de Tabebuia chrysotricha de janeiro a dezembro de 2010 (Figura 2) mostraram que o período de floração das espécies plantadas na calçada pavimentada foi mais curto e se iniciou mais tarde do que os indivíduos do canteiro central. As espécies do canteiro central apresentaram encerramento da frutificação e início do período sem folhas mais cedo, do que as espécies plantadas na calçada pavimentada.

Figura 2. Fenofases reprodutivas e vegetativas de Tabebuia chrysotricha

Figure 2. Reproductive and vegetative phenophases of $T$. chrysotricha

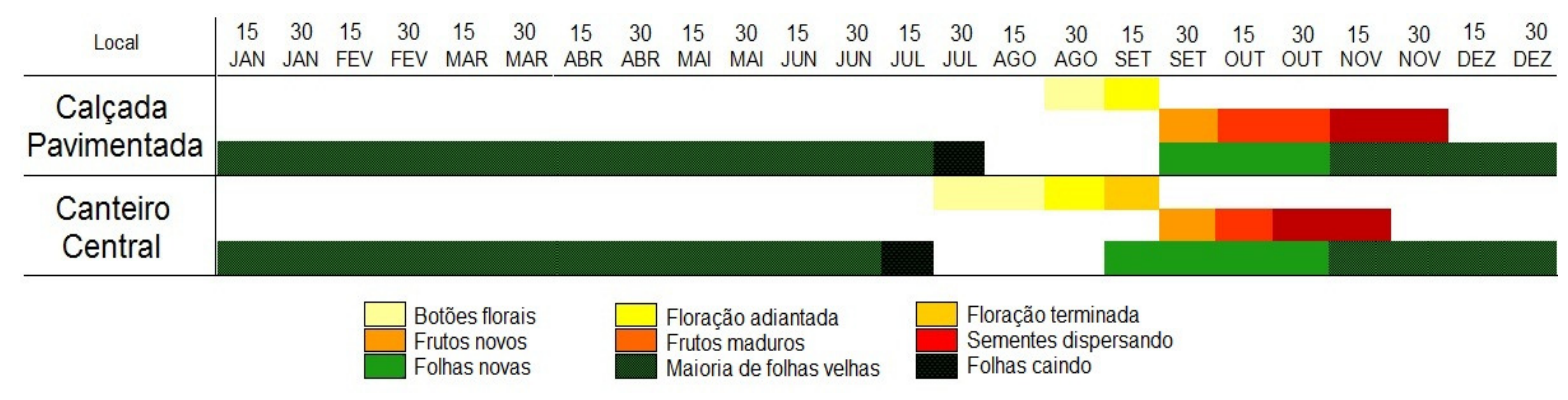

Com base na Figura 2, nota-se que a floração dos exemplares da calçada pavimentada durou um mês (agosto-setembro), enquanto que os indivíduos do canteiro central apresentaram floração por dois meses (julho-setembro). Desta forma, a floração das espécies plantadas na calçada pavimentada foi mais curta e se iniciou mais tarde do que os indivíduos do canteiro central.

Segundo Biondi (1990) o valor ornamental da floração é incontestável, e por mais discreta que seja a sua apresentação, é o fenômeno mais aguardado devido principalmente à cor.

Desta forma a espécie se torna mais apreciada, quanto maior for o tempo de permanência da flor, o que favorece os indivíduos do canteiro central. Em trabalho realizado para avaliar o efeito da poda em algumas espécies da arborização de Santa Maria-RS, Brun 
et al. (2007), concluíram que o ipê-amarelo é a espécie que melhor aceita essa prática, sendo até um fator de indução para a ocorrência da floração.

Esse menor período de floração dos indivíduos da calçada pavimentada pode ser também satisfatório, já que muitos cidadãos se sentem incomodados com a "sujeira" que podem ser geradas pelas plantas: perda de folhas, flores e frutos (SILVA; PAIVA; GONÇALVES, 2007). Essa visão, de que às árvores sujam muito a calçada ou entopem calhas e condutor é um dos fatores levantados constantemente pelos moradores durante a escolha de uma espécie a se plantar (IPEF, 2010).

A floração das espécies ocorreu dentro do período indicado por Lorenzi (1992). Para os indivíduos do canteiro central, o início foi antecipado. Brun et al. (2007), em Santa Maria, encontraram um período de floração de julho a outubro e Palioto et al. (2007), no Campus da Universidade Estadual de Maringá, de julho a outubro.

A frutificação dos exemplares ocorreu de setembro a novembro nos dois ambientes apresentando-se mais longa do que as apresentadas por Lorenzi (1992) e Backes e Irgang (2004). Estes indicam um término de frutificação no mês de outubro, mas o encerramento e término da dispersão de sementes, ocorreu em novembro, apresentando resultado igual à Palioto et al. (2007). Já, Brun et al. (2007) encontrou período de frutificação entre agosto e dezembro.

Os indivíduos da calçada pavimentada e do canteiro central se apresentaram sem folhas por um mês e meio, entretanto, os indivíduos do canteiro central apresentaram o início deste período mais cedo.

O período em que as espécies se apresentaram desfolhadas no meio urbano corresponde ao mesmo período indicado por Lorenzi (1992). Não houve variação na duração desse período entre os ambientes, apenas mudou a época de ocorrência. A desfolha foi observada entre os meses de junho e outubro por Brun et al. (2007) e de junho a setembro por Palioto et al. (2007).

Biondi, Reissmann e Batista (1999) afirmam, que a varrição das folhas nas calçadas faz com que elementos como $\mathrm{Ca}, \mathrm{Mg}, \mathrm{Fe}, \mathrm{Mn}, \mathrm{Cu}$ e $\mathrm{Al}$ deixem de ser incorporados ao solo para o processo de ciclagem, podendo haver deficiências de micronutrientes pela quebra no processo da ciclagem natural dos elementos. Este processo pode ser responsável pela distinção fenológica encontrada entre os ambientes.

\section{Relação das Fenofases com o Clima}

$\mathrm{Na}$ Figura 3, é apresentado o comportamento dos elementos meteorológicos distribuídos mensalmente entre janeiro e dezembro de 2010. Observa-se que a temperatura

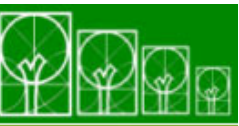

$\mathbf{S} \cdot \mathbf{B} \cdot \mathbf{A} \cdot \mathbf{U}$ Soc. Bras. de Arborização Urbana

REVSBAU, Piracicaba - SP, v.6, n.4, p. 51-67, 2011 
média mais baixa foi na primeira quinzena de agosto $\left(11,2^{\circ} \mathrm{C}\right)$ e a mais alta na primeira quinzena de fevereiro $\left(24,1^{\circ} \mathrm{C}\right)$. A umidade relativa do ar teve seu ponto mais baixo na segunda quinzena de agosto $(67,8 \%)$ e o ponto mais alto na primeira quinzena de janeiro $(91,2 \%)$. A precipitação foi mais baixa na segunda quinzena de agosto $(0,0 \mathrm{~mm})$ e a mais alta na primeira quinzena de março $(132,8 \mathrm{~mm})$. Já o fotoperíodo apresenta seu ponto mais baixo no mês de junho $(10,5 \mathrm{~h})$ e o ponto mais alto em dezembro $(13,7 \mathrm{~h})$.

Figura 3. Temperatura média (A), Umidade Relativa do $\operatorname{Ar}(B)$, Fotoperíodo (C), Distribuição da Precipitação (D)

Figure 3. Average temperature (A), Relative Humidity (B), Photoperiod (C), Distribution of Precipitation (D)
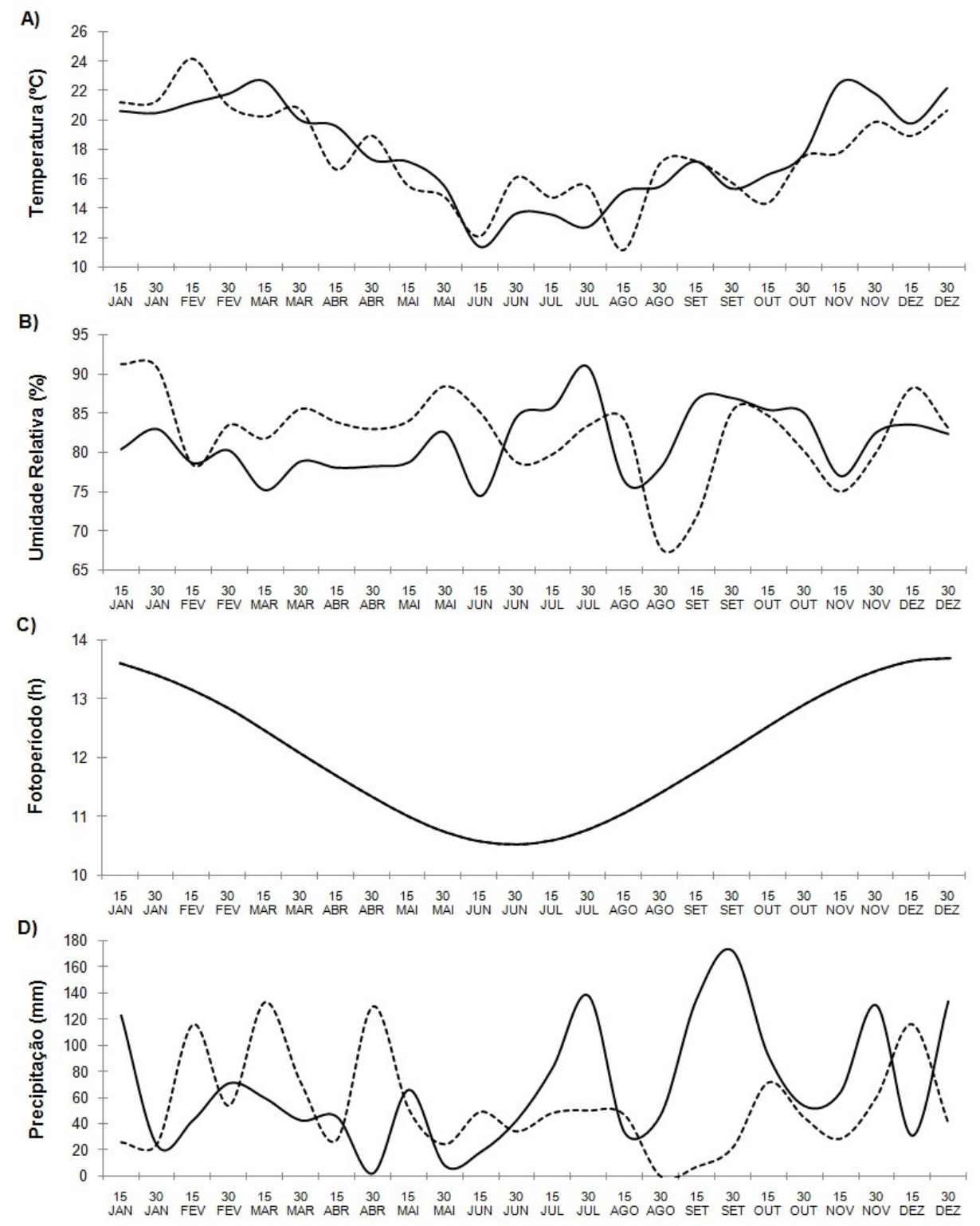

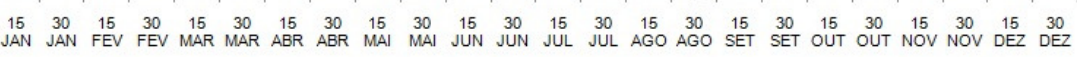

-2009 -----2010 
O ano de 2010 apresentou temperatura média de $17,4^{\circ} \mathrm{C}$, umidade relativa de $82,4 \%$, fotoperíodo médio de $12,1 \mathrm{~h}$ e precipitação de $1276,70 \mathrm{~mm}$.

$\mathrm{Na}$ Figura 4, é apresentada a distribuição das fenofases de Tabebuia chrysotricha com maior relevância para o estudo, distribuídas mensalmente entre janeiro e dezembro de 2010. Junto a cada uma destas, são ilustradas as demais fenofases que compõem o mesmo processo - floração, frutificação e foliação.

Figura 4. Produção de botões (A), Dispersão de sementes (B), Produção de folhas novas (C)

Figure 4. Production of buttons (A), Seed dispersal (B), Production of new leaves (C)

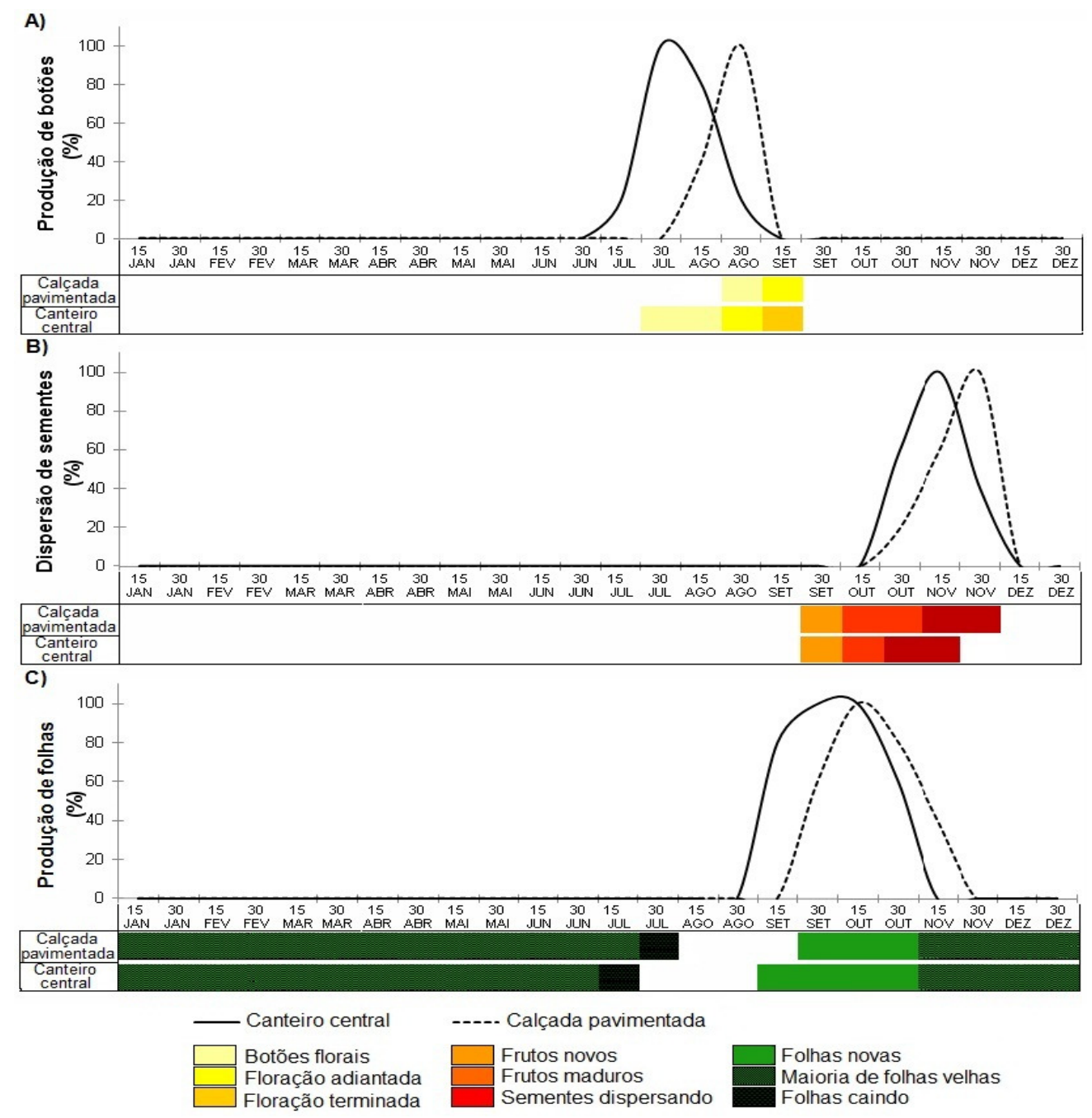

Com base nas Figuras 3 e 4, é possível observar que a produção de botões dos indivíduos da calçada pavimentada ocorreu logo após as menores temperaturas e 
fotoperíodo superior a $11 \mathrm{~h}$. O período com flores abertas e encerramento da floração ocorreu no período de menores precipitações. Os indivíduos do canteiro central apresentaram floração mais longa. Kerbauy (2004) relata que, no início do século XX, J. Gustav Gassner observou a necessidade de temperaturas abaixo de determinado valor para a formação de flores em certas espécies.

Embora a produção de botões tenha ocorrido antes nestes indivíduos do que nos indivíduos da calçada pavimentada, a ocorrência de um período com baixas temperaturas e maior precipitação, logo após o início desta fenofase, fez com que a produção se estagnasse por alguns dias e retornasse após o aumento das temperaturas e diminuição da precipitação. Devido a esta situação, a florada dos ipês plantados na calçada pavimentada se mostrou mais intensa e vistosa do que as do canteiro central (Figura 5).

Figura 5. Diferença de fases fenológicas em calçada e canteiro central

Figure 5. Difference in phenological phases in paved sidewalks and central bed

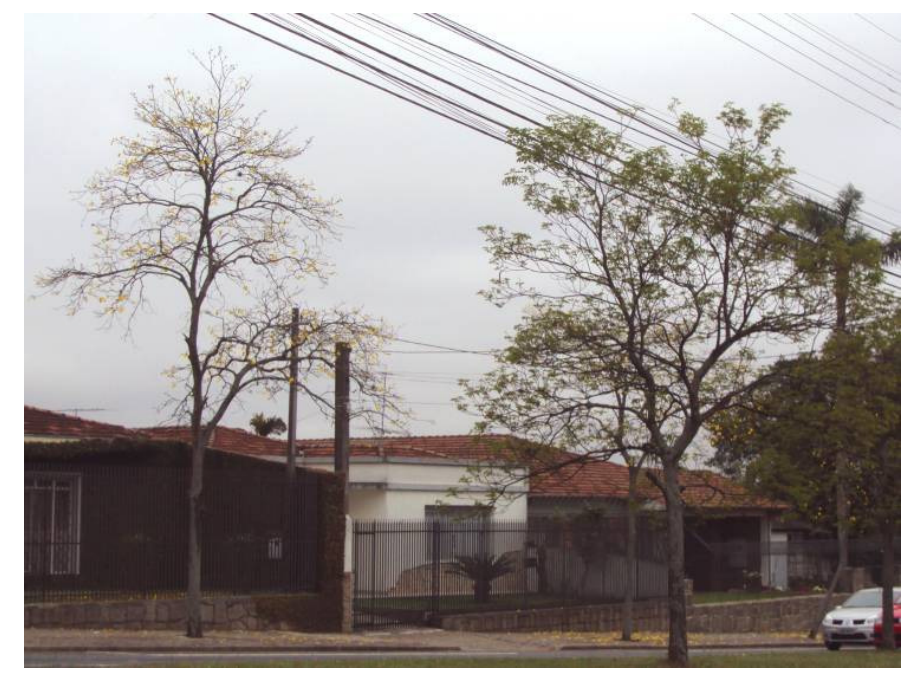

Os indivíduos do canteiro central apresentaram frutificação mais curta. A produção de frutos coincidiu com o pico de alta precipitação e umidade relativa e a dispersão de sementes ocorreu em altas temperaturas. Os indivíduos de T. chrysotricha demonstraram que a formação dos frutos ocorre nos picos de alta precipitação, bem como de maior umidade relativa. Conforme Ometto (1981), o comportamento da vegetação é fortemente associado à umidade atmosférica.

No estudo realizado por Biondi (1995), árvores de Acer negundo cultivadas em calçada pavimentada apresentaram ausência de frutos maior do que as árvores plantadas no canteiro central. Geralmente as condições do ambiente urbano favorecem a alteração da 
freqüência e quantidade de frutos na árvore. Por exemplo, a iluminação, é um dos fatores que mais influencia a floração das árvores.

A produção de novas folhas ocorreu quando as temperaturas aumentaram e a precipitação foi baixa. Já o período sem folhas iniciou-se num pico de alta precipitação, mas variou entre os ambientes. Iniciou mais tarde nos indivíduos da calçada pavimentada. $\mathrm{O}$ que pode indicar um problema na drenagem do solo. Uma vez que as árvores em ambientes urbanos, especialmente quando plantadas em calçadas, ficam sob estresse hídrico e nutricional por longos períodos (WIERSUM; HERMANNY, 1983).

De maneira geral, é possível observar nos gráficos da Figura 4 que as fenofases apontadas como principais (produção de botões, dispersão de sementes e produção de novas folhas), ocorreram mais tarde nos indivíduos da calçada pavimentada do que nos indivíduos do canteiro central.

Deve-se lembrar que a permeabilidade do solo varia conforme o material que 0 recobre e isto exerce influência sobre a dinâmica das águas pluviais e sobre o desenvolvimento das espécies arbóreas. Os gramados e outros vegetais de forração do solo, ao contrário das superfícies impermeáveis, contribuem para o manejo de água no solo, sua retenção, filtração e purificação (BOBROWSKI; BIONDI; BAGGENSTOSS, 2009).

\section{CONCLUSÔES}

O acompanhamento fenológico realizado mostrou que as variáveis meteorológicas influenciam no comportamento da espécie, bem como as formas de plantio a que as árvores estudadas estão submetidas na avenida. Possibilitou também determinar a época e a duração das fases reprodutivas e vegetativas da espécie estudada em cada condição ou forma de plantio.

Os indivíduos plantados em calçadas pavimentadas apresentam dimensões maiores do que os indivíduos do canteiro central com gramado, estes com maior área de permeabilidade.

Embora a floração das árvores plantadas em canteiro central tenha sido mais longa, os indivíduos da calçada pavimentada apresentaram floração mais intensa e vistosa em um menor intervalo de tempo. A produção de botões florais, dispersão de sementes e produção de novas folhas iniciou mais tarde nos indivíduos plantados em calçada pavimentada. 


\section{REFERÊNCIAS BIBLIOGRÁFICAS}

BACKES, P.; IRGANG, B. Mata Atlântica: As Árvores e a Paisagem. Porto Alegre: Paisagem do sul, 2004. 396p.

BIONDI, D. Paisagismo. Recife: Imprensa Universitária da UFRPE, 1990. 184p.

BIONDI, D. Caracterização do estado nutricional de Acer negundo L. e Tabebuia chrysotricha (Mart. ex DC.) Standl. utilizadas na arborização urbana de Curitiba-PR. 1995. 160f. Tese (Doutorado em Ciências Florestais) - Universidade Federal do Paraná, Curitiba. 1995.

BIONDI, D. Arborização Urbana - Aplicada à Educação Ambiental nas Escolas. Curitiba: $O$ Autor, 2008. 120p.

BIONDI, D.; ALTHAUS, M. Árvores de Rua de Curitiba - Cultivo e Manejo. Curitiba: FUPEF, 2005. 175p.

BIONDI, D.; REISSMANN, C. B.; BATISTA, A. C. Exportação de nutrientes devido a varrição das folhas de Acer negundo L. plantado nas ruas de Curitiba-PR. In: 50 Congresso Nacional de Botânica, 1999, Blumenau. Anais... Blumenau: SBB-FURB-UFSC-UNESC-HBREPAGRI,. v. 1. 1999. p. 103.

BOBROWSKI, R.; BIONDI, D.; BAGGENSTOSS, D. Composição de canteiros na arborização de ruas de curitiba (PR). Revista da Sociedade Brasileira de Arborização Urbana, Piracicaba - SP, v.1, n.1, p.44-61, 2009.

BRADSHAW, A.; HUNT, B.; WALMSLEY, T. Trees in the Urban Landscape: Principles and practice. Liverpool, Reino Unido: E \& FN Spon, 1995. 272p.

BRUN, F. G. K.; LONGHI, S. J.; BRUN, E. J.; FREITAG, A. S.; CHUMACHER, M. V. Comportamento fenológico e efeito da poda em algumas espécies empregadas na arborização do bairro Camobi - Santa Maria, RS. Revista da Sociedade Brasileira de Arborização Urbana, v.2, n.1, 2007.

FEIBER, F. N. Áreas verdes, identidade e gestão urbana: estudo de caso na região central de Curitiba - Paraná. 2005. 189f. Tese (Mestrado em Gestão Urbana de Produção) - Centro de Ciências Exatas e Tecnologia, Pontifícia, Universidade Católica do Paraná. Curitiba. 2005. 
IPEF - Instituto de Pesquisas e Estudos Florestais. Arborização Urbana. Disponível em: <http://www.ipef.br/silvicultura/arborizacaourbana.asp>. Acesso em: 11 mai. 2010.

IPPUC - Instituto de Pesquisa e Planejamento Urbano de Curitiba. Curitiba em dados - 2006. Disponível

em: <http://ippucnet.ippuc.org.br/Bancodedados/Curitibaemdados/anexos/2001_Características \%20do\%20Relevo\%20de\%20Curitiba.pd f>. Acesso em: 13 jun. 2008.

KERBAUY, G. B. Fisiologia Vegetal. Rio de Janeiro: Ed. Guanabara Koogan, 2004. 452 p.

LARCHER, W. Ecologia Vegetal. São Carlos: RiMa, 2006. 550p.

LORENZI, H. Árvores Brasileiras: Manual de Identificação e Cultivo de plantas nativas do Brasil. Nova Odessa: Editora Plantarum, 1992. 352p.

MARQUES, M.C.M.; OLIVEIRA, P.E.A.M. Fenologia de espécies do dossel e do sub-bosque de duas Florestas de Restingas na Ilha do Mel, sul do Brasil. Revista Brasileira de Botânica, 27(4): 713-723, 2004.

MARTINI, A.; BIONDI, D.; BATISTA, A. C.; NATAL, C. M. Fenologia de espécies nativas com potencial paisagístico. Semina, Londrina, v. 31, n. 1, p. 75-84, jan./mar, 2010.

MILANO, M. S.; DALCIN, E. C. Arborização de vias públicas. Rio de Janeiro: Light, 2000. $206 p$.

OMETTO, J. C. Bioclimatologia Vegetal. São Paulo: Ed. Agronômica Ceres, 1981. 425p.

PALIOTO, G. F.; SUGIOKA, D. K.; CODA, J.; ZAMPAR, R.; LAZARIN, M. O.; LOYOLA, M. B. P.; RUBIN FILHO, C. J. Fenologia de espécies arbóreas no Campus da Universidade Estadual de Maringá. Revista Brasileira de Biociências, Porto Alegre, v. 5, supl. 1, p. 441443, jul, 2007.

PEDROSA, J.B. Arborização de cidades e rodovias. Belo Horizonte: IEF/MG, 1983. 64 p.

RAMALHO, R. S. Dendrologia. v.1. Viçosa: UFV, 1976. 123p.

SANTOS, N. R. Z.; TEIXEIRA, J. F. Arborização de vias públicas: ambiente x vegetação. Santa Cruz do Sul: Instituto Souza Cruz, 2001. 135p.

SCHUBERT, T. H. Trees for urban use in Puerto Rico and The Virgin Islands. Rio Piedras, Porto Rico: USDA Forest Service, 1979. 91p.

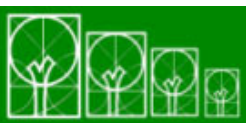

S $\cdot \mathbf{B} \cdot \mathbf{A} \cdot \mathbf{U}$ Soc. Bras. de Arborização Urbana 
SILVA, A. G.; PAIVA, H. N de; GONÇALVES, W. Avaliando a arborização urbana. Jardinagem e paisagismo. Arborização urbana; 5. Viçosa: Aprenda Fácil, 2007. 346p.

WIERSUM, L. K.; HARMANNY, K. Changes in the water- permeability of roots of some trees during drought stress and recovery, as related to problems of growth in urban environment. Plant and Soil, The Hague, v.75, n.3, p.443-448, 1983. 